\title{
Transcatheter aortic valve implantation: The European experience
}

\author{
Rüdiger Lange, MD, PhD, ${ }^{\mathrm{a}}$ Sabine Bleiziffer, MD, ${ }^{\mathrm{a}}$ Yacine Elhmidi, MD, ${ }^{\mathrm{a}}$ and Nicolo Piazza, MD, PhD ${ }^{\mathrm{a}, \mathrm{b}}$
}

The European transcatheter aortic valve implantation experience began in 2002, and ever since, numerous centers have started a program, resulting in a "transcatheter aortic valve implantation pandemic." Considerable experience has been gained with various access routes for implantation and with valve-in-surgical bioprosthetic valve procedures. Reimbursement differs among the European countries and is currently undergoing rapid changes. Accordingly, the implantation rates in various European countries still differ considerably, with the greatest in Switzerland and Germany: 77 implants per 1 million treatable inhabitants. The Edwards Source and the Medtronic Advance trials, designed as postcommercialization studies, demonstrated a steady improvement in results, which was also reflected in the single-center mid-term data up to 3 years. The preliminary results from national European registries have been remarkably comparable in terms of survival and stroke. The "glimpse into the future" points toward implantation in intermediate-risk patients in contrast to high-risk or inoperable patients. The results of the Medtronic Surgical Replacement and Transcatheter Aortic Valve Implantation and Edwards Placement of Aortic Transcatheter Valves Trial 2 trials will show whether this change in paradigm is justified. (J Thorac Cardiovasc Surg 2013;145:S17-21)

The European transcatheter aortic valve implantation (TAVI) experience began in 2002, when Alain Cribier, 1 of the pioneers of transcatheter valves, implanted the first balloon expandables Cribier-Edwards prosthesis using a trans-septal approach in a 57-year-old male patient with severe aortic stenosis in whom conventional aortic valve replacement had been declined. ${ }^{1}$ In 2006 , Grube and colleagues $^{2}$ published their first-in-man single-center experience with 25 patients who underwent retrograde implantation of the self-expandable CoreValve ReValving bioprosthesis. The Medtronic CoreValve (Medtronic, Minneapolis, Minn) and the Edwards SAPIEN (Edwards LifeSciences, Irvine, Calif) prostheses obtained CE mark approval in April 2007 and August 2007, respectively. In October 2011, the Jena Valve (JenaValve Technology $\mathrm{GmbH}$, Munich, Germany) and the Symetis Acurate TA (Symetis, Ecublens, Switzerland) received CE mark approval for transapical aortic valve implantation (Figure 1). ${ }^{3}$

\section{EXPERIENCE WITH VARIOUS ACCESS ROUTES}

In Europe, TAVI is currently performed using a transfemoral, transaxillary, transapical, and transaortic approach. $^{4-9}$ The carotid artery has also been used as

\footnotetext{
From the Department of Cardiovascular Surgery, ${ }^{\text {a }}$ Technische Universität München, German Heart Center Munich, Munich, Germany; and Department of Interventional Cardiology, ${ }^{\text {b }}$ McGill University Health Center, Royal Victoria Hospital, Montreal, Quebec, Canada.

Disclosures: Drs Lange, Bleiziffer, Elhmidi, and Piazza have nothing to disclose with regard to commercial support.

Read at The American Association for Thoracic Surgery Aortic Symposium, New York, New York, April 26-27, 2012.

Received for publication April 26, 2012; revisions received Sept 18, 2012; accepted for publication Nov 28, 2012.

Address for reprints: Sabine Bleiziffer, MD, Department of Cardiovascular Surgery, Technische Universität München, German Heart Center Munich, Lazarettstr 36, Munich 80636, Germany (E-mail: bleiziffer@dhm.mhn.de). $0022-5223 / \$ 36.00$

Copyright (c) 2013 by The American Association for Thoracic Surgery http://dx.doi.org/10.1016/j.jtcvs.2012.11.049
}

a successful access route. ${ }^{10}$ After the first-in-man description of the subclavian and transaortic access approach in 2008 and 2009, respectively, many single- and multicenter reports have emerged. ${ }^{11,12}$ The results and techniques for the transaortic approach were presented at the Annual Society of Thoracic Surgeons meeting in $2012^{13,14}$ (Table 1).

\section{TRANSCATHETER AORTIC VALVE IN SURGICAL AORTIC VALVE IMPLANTATION}

Danny Dvir, MD, of the Rabin Medical Center (Petah Tikva, Israel) presented data from the Global Valve-in-Valve Registry at the 2011 Transcatheter Cardiovascular Therapeutics 23rd Annual Scientific Symposium. ${ }^{15}$ The Medtronic CoreValve and Edwards Sapien prostheses were implanted in $63 \%$ and $37 \%$ of the 195 patients, respectively. The investigators concluded that the technique is clinically effective in most patients and that the 1-year results were comparable with other TAVI experience. It was emphasized, however, that the procedures are technically demanding and should be reserved for high-volume centers. Ostial left main obstruction can be a concern, especially when using specific bioprosthetic devices. ${ }^{16,17}$ Significantly elevated postprocedural gradients were commonly observed in relatively small bioprosthetic devices treated with currently available Edwards Sapien prostheses.

\section{EUROPEAN MARKET}

To date, more than 60,000 transcatheter aortic valve prostheses have been implanted worldwide. Although the annual growth rate has slowed, in 2011, it was still $47 \%$ (BIBA Medical Ltd, London, United Kingdom; a provider of market analysis for the medical device industry). The total number of implants has varied among the major European countries. According to the official statistics of the German Society for Thoracic and Cardiovascular Surgery, 5083 TAVI procedures were performed in 2011, accounting 


$\begin{array}{cl}\text { Abbreviations and Acronyms } \\ \text { euroSCORE }= & \text { European System for Cardiac } \\ & \text { Operative Risk Evaluation } \\ & =\text { health technology assessment } \\ \text { HTA } & \text { transapical } \\ \text { TA } & \text { transcatheter aortic valve } \\ \text { TAVI } & \text { implantation } \\ & =\text { transfemoral }\end{array}$

for $30.5 \%$ of all isolated aortic valve procedures in Germany (DGTHG Leistungsstatistik 2011). Nonetheless, TAVI penetration rates have been less than $20 \%$ in Europe, according to data presented by Nicolo Piazza, MD, at the 2011 PCR London Valves Congress in London, United Kingdom. The distribution of implant procedures for the main European countries was as follows: Germany, $43 \%$; Italy and France, 11\%; Spain and United Kingdom, 7\%; The Netherlands, $6 \%$; and Switzerland, $4 \%$. The number of implants per 1 million inhabitants was greatest for Switzerland and Germany, with 77 implants per 1 million, followed by Austria at 50/1 million, The Netherlands at 49/1 million, Belgium at 40/1 million, Denmark at 39/1 million, Italy at $27 / 1$ million, France at $24 / 1$ million, Spain at 21/1 million, Sweden at 20/1 million, Finland at $17 / 1$ million, United Kingdom/Ireland at 16/1 million, Portugal at 13/1 million, and Norway at 12/1 million, respectively (BIBA Medical Ltd).

\section{REIMBURSEMENT}

A health technology assessment (HTA) describes the systematic evaluation of health-relevant procedures and methods (ie, vaccinations, medical treatments, preventative measures) and examines the effectiveness, safety, and economic viability of a health intervention, as well as its social, ethical, legal, and organizational effects and thus serves as the basis for decisions in the health system (DIMDI, German Institute of Medical Documentation and Information, Cologne, Germany). Such a systematic evaluation of TAVI has not yet been performed in all European countries.

According to the data presented by Nicolo Piazza, MD, at the 2011 PCR London Valves Congress in London, United Kingdom, the United Kingdom has not yet performed an HTA, because they await randomized trial data. The TAVI procedures are thus funded within the hospital budget. In Belgium and The Netherlands, the HTA review provided negative findings, with clinical data only (no economic data), and funding was declined. In these hospitals, TAVI procedures are funded within the hospital budget. In Germany, an HTA review is currently not required. After CE mark approval, the respective diagnosis-related group reimbursement system is sufficient to cover the procedures. In Italy, a regional HTA is ongoing, and reimbursement is also regional. In Spain, the regional HTA is still ongoing, and the TAVI procedures are funded within the hospital budget. In France, there was a national HTA, resulting in a positive HTA review from clinical data only (no economic data), and implantations are restricted to 33 implanting centers and inoperable patients.

Hence, the TAVI reimbursement process is different across the European countries. Reimbursement assessment can be performed at a national or regional level, and in different countries, reimbursement might or might not require a formal HTA review process. In summary, reimbursement for TAVI is a dynamic process that is currently undergoing rapid change.

\section{MAJOR INDUSTRY-SPONSORED EUROPEAN STUDIES}

Two postcommercialization studies have been performed, both of which were sponsored by the manufacturer of the respective valve prosthesis used.

The first trial was the Edwards SOURCE TA and TF Trial using the Edwards SAPIEN prosthesis (Edwards LifeSciences). The 1-year analysis ( $97.9 \%$ compliance) of the entire cohort of 2307 patients for this multicenter study was presented by Dr Olaf Wendler (Kings College Hospital, London, United Kingdom) at the EuroPCR 2011: Congress of the European Association of Percutaneous Cardiovascular Interventions (May 17-20, 2011, Paris, France). ${ }^{18}$

Significant differences were seen between the transfemoral (TF) ( $\mathrm{n}=920)$ and transapical (TA) $(\mathrm{n}=1387)$ groups, with a significantly greater rate of comorbidities in the TA group. Adverse events up to 30 days showed no differences between the TF and TA groups regarding the incidence of stroke $(2.9 \%$ and $2.5 \%)$, acute myocardial infarction $(0.9 \%$ and $0.5 \%)$, perivalvular leakage greater than aortic regurgitation $2+(6.7 \%$ and $4.3 \%)$, and endocarditis. However, significantly more major bleeding events $(6.7 \%$ vs $1.8 \%, P<.04)$ and a greater incidence of renal failure requiring dialysis $(3.9 \%$ vs $2.3 \%, P<.001)$ were observed in the TA than in the TF group. In contrast, the TF group exhibited significantly more major vascular access-related complications $(11.3 \%$ vs $2.0 \%, P<.001)$. For the entire cohort of 2307 patients, the overall 30-day and 1-year survival was $90.5 \%$ and $76.5 \%$, respectively. For the TF group, the corresponding percentages were $92.5 \%$ and $81.1 \%$ and for the TA group were $89.1 \%$ and $74.2 \%$.

The second trial was the Medtronic Advance Trial with the Medtronic CoreValve prosthesis. The Medtronic Advance Study was designed to evaluate the safety, efficacy, and clinical outcomes, using the Valve Academic Research Consortium criteria, of the CoreValve system in 1015 consecutive "real world" patients with severe aortic stenosis. Major complications included valve embolization in 


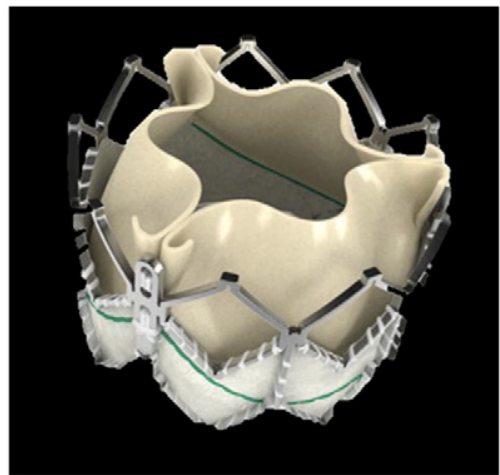

A

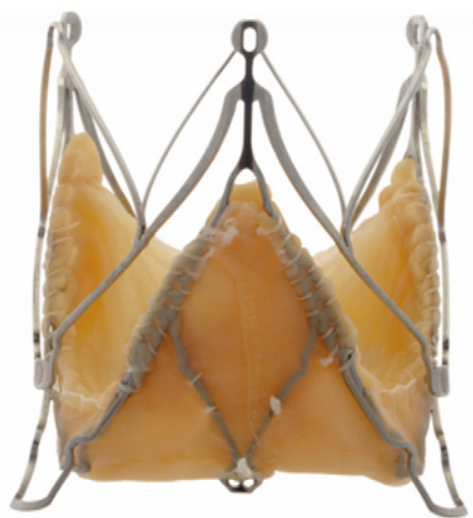

C
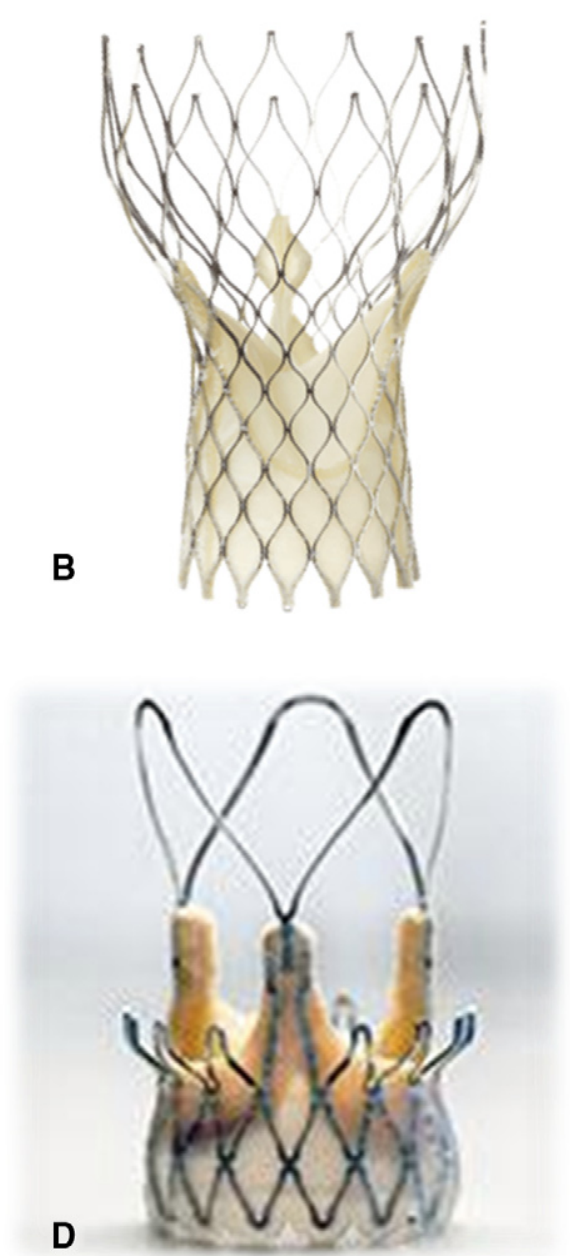

FIGURE 1. Currently approved CE mark transcatheter aortic valves: A, Edwards SAPIEN XT; B, Medtronic CoreValve; C, JenaValve; and D, Symetis.

$0.3 \%$, the need for conversion to open aortic valve replacement in $0.1 \%$, and compromise of coronary perfusion in $0.1 \%$. The effective orifice area remained unchanged for up to 6 months, and symptomatic improvement in terms of New York Heart Association class was observed in almost all patients. All-cause mortality at 30 days or less was $4.5 \%$, and cardiovascular mortality was $3.4 \%$. The incidence of stroke was $2.9 \%$, major bleeding events were observed in $9.7 \%$, vascular access site complications in $10.7 \%$, and acute kidney injury in $0.4 \%$. Also, $26.3 \%$ of the patients required new permanent pacemaker implantation. The 6-month survival stratified by European System for Cardiac Operative Risk Evaluation (euroSCORE) was $95.7 \%$ for those with a euroSCORE of $0 \%$ to $10 \%$, $92.4 \%$ for a euroSCORE of $10 \%$ to $20 \%$, and $88.1 \%$ for those with a euroSCORE greater than $20 \%$.

\section{EUROPEAN SINGLE-CENTER MID-TERM EXPERIENCE}

In 4 major European single-center studies, the mean aortic gradient and effective orifice area were shown to remain unchanged for up to 3 years after implantation of the Medtronic CoreValve prosthesis and Edwards Sapien prosthesis. ${ }^{19-22}$ Their results (Table 2) demonstrated strikingly

TABLE 1. Transaortic series

\begin{tabular}{lccccc}
\hline Investigator & Patients (n) & Technique & Prosthesis & 30-d Mortality (\%) & Stroke incidence (\%) \\
\hline Moat $^{13}$ & 93 & $\begin{array}{c}\text { Right minithoracotomy in } 52.2 \% ; \\
\text { upper ministernotomy in } 47.5 \%\end{array}$ & CoreValve & $9.7 \%$ & $3.2 \%$ \\
Bapat $^{14}$ & 158 & $\begin{array}{c}\text { Upper ministernotomy in 87\%; } \\
\text { right minithoracotomy in 13\% }\end{array}$ & Sapien & $7 \%$ & $0 \%$ \\
\hline
\end{tabular}


TABLE 2. Survival up to 3 years with CoreValve and Sapien valves

\begin{tabular}{|c|c|c|c|c|c|}
\hline \multirow[b]{2}{*}{ Author } & \multirow[b]{2}{*}{ Patients (n) } & \multirow[b]{2}{*}{ Prosthesis } & \multicolumn{3}{|c|}{ Survival (\%) } \\
\hline & & & $1 \mathbf{y}$ & $2 y$ & $3 \mathbf{y}$ \\
\hline Walther et $\mathrm{al}^{19}$ & 299 & Sapien & $73 \%$ & $68 \%$ & $58 \%$ \\
\hline Ussia et $\mathrm{al}^{20}$ & 181 & CoreValve & $76.4 \%$ & $69.7 \%$ & $56.2 \%$ \\
\hline Bleiziffer et $\mathrm{al}^{21}$ & 227 & $\begin{array}{l}\text { Sapien plus } \\
\text { CoreValve }\end{array}$ & $74.5 \%$ & $64.4 \%$ & - \\
\hline${\text { Buellesfeld et } \mathrm{al}^{22}}^{22}$ & 126 & CoreValve & - & $61.9 \%$ & 一 \\
\hline
\end{tabular}

similar mid-term survival data, regardless of the access route or prosthesis type used.

\section{EUROPEAN REGISTRIES}

Data are available from the national registries of 6 different European countries: Germany (1387 patients), the United Kingdom (877 patients), Belgium (600 patients), Italy (663 patients), France (2419 patients), and Spain (108 patients). ${ }^{23,24}$ All registries included the Medtronic CoreValve and Edwards Sapien prostheses. It is remarkable that a trend toward a decrease in the euroSCORE over time was observed in most registries and that the overall results in terms of adverse events and survival have been comparable. However, these very early registry data should be regarded with caution. In some countries, such as Germany, an obligatory national registry was only recently started, and the results are not yet available. The registry cited in the present report was from a multicenter German study that does not reflect the entire German data set. Similarly, in other countries, the registries might report very early results and be incomplete. Furthermore, not all registries collect the data according to the same standards, such as the Valve Academic Research Consortium criteria; thus, comparisons among different registry results might not be accurate.

The logistic euroSCORE of patients reported in these registries lies within a small range: from $20.5 \%$ (in Germany) to $26 \%$ (in Belgium). The only outlier was Spain at $16 \%$. The 30-day and 1-year survival have been reported to be in the range of $88.8 \%$ (in Germany) to $94.6 \%$ (in the United Kingdom) and from $76 \%$ (in France) to $85 \%$ (in Italy). In contrast, a marked difference has been reported in the incidence of vascular complications, ranging from $3.9 \%$ in the United Kingdom up to $16.9 \%$ in Germany. This considerable variation could also reflect different standards for data reporting and the use of different access routes.

Recently, a true National German Aortic Registry was established, and enrollment started in December 2010. This registry compiles the data of all surgical and transcatheter aortic valve procedures in Germany. Participation is mandatory, and nonreporting centers are published in the "Journal of the Deutsche Herzstiftung" (German Heart Foundation). By April 19, 2012, 22,473 patients had given consent, and their data were being transmitted to the registry. Of the procedures reported, $71 \%$ were conventional aortic valve replacements, $20 \%$ transarterial TAVI procedures, $8 \%$ transapical TAVI procedures, and $1 \%$ valvuloplasties. Data from this registry were reported for the first time at the 2012 European Society of Cardiology Congress in Munich, Germany (August 25-29, 2012).

\section{A GLIMPSE OF THE FUTURE}

Similar to coronary stent use for off-label indications, evidence has shown that, in Europe, the patient selection criteria for TAVI are evolving away from the premarket inclusion and exclusion criteria. Thus, it seems that transcatheter aortic valves are being implanted in lower risk patients than those originally included in the initial safety and feasibility trials. We recently published a study in which 420 patients undergoing TAVI were subdivided into 4 equal quartiles (each quartile with 105 patients) according to the enrollment period. ${ }^{25}$ The 4 subgroups were subsequently analyzed for differences in baseline characteristics and clinical outcomes. The crude 30-day and 6-month mortality rates improved from quartile 1 to quartile 4 . However, after adjustment for patient risk factors, no significant differences in mortality were observed between the quartiles, suggesting that changing baseline characteristics might, in part, explain the observed differences in crude mortality. We observed a shift toward the treatment of younger patients with fewer comorbidities and lower surgical risk (logistic euroSCORE and Society of Thoracic Surgeons score). The results of that study suggested that improved survival outcomes can be expected in lower surgical risk patients undergoing TAVI.

The extent of this paradigm shift and its effect on clinical outcomes, however, are still uncertain. The Medtronic CoreValve Surgical Replacement and Transcatheter Aortic Valve Implantation (SURTAVI) trial and Edwards Placement of AoRTic TraNscathetERValve (PARTNER 2) SAPIEN XT trial will randomize intermediate- to highsurgical risk patients to TAVI or surgical aortic valve replacement. These trials should provide us with yet another indication that TAVI is being directed at the treatment of lower risk and lower surgical risk patients.

The SURTAVI trial, which started enrollment in April 2012, is expected to randomize 2000 patients older than 70 years with aortic stenosis and at intermediate surgical risk (defined by an Society of Thoracic Surgeons score of 3\%-10\% in Europe and Canada and 4\%-10\% in the United States) to conventional surgery or TAVI with the Medtronic CoreValve. In the PARTNER 2 trial, intermediate-risk patients are randomized after the decision regarding TF or TA access to surgery or TAVI. These are noninferiority trials, with primary endpoints of all-cause mortality and major stroke at 2 years. 


\section{CONCLUSIONS}

The European TAVI experience began in 2002, and ever since, numerous centers have started a program, resulting in a "TAVI pandemic." Considerable experience has been gained with various access routes for implantation and with valve in surgical bioprosthetic valve procedures. Reimbursement differs among the European countries and is currently undergoing rapid changes. Accordingly, implantation rates in various European countries still differ considerably, with the greatest in Switzerland and Germany: 77 implants/ 1 million treatable inhabitants. The Edwards Source and the Medtronic Advance trials, designed as postcommercialization studies, have demonstrated a steady improvement in results, which was also reflected in the single-center mid-term data up to 3 years. Preliminary results from the national European registries have been remarkably comparable in terms of survival and stroke. The "glimpse into the future" points toward implantation in intermediate-risk patients instead of high-risk or inoperable patients. The results of the Medtronic SURTAVI and Edwards PARTNER 2 trial will show whether this change in paradigm is justified.

\section{References}

1. Cribier A, Eltchaninoff H, Bash A, Borenstein N, Tron C, Bauer F, et al. Percutaneous transcatheter implantation of an aortic valve prosthesis for calcific aortic stenosis: first human case description. Circulation. 2002;106:3006-8.

2. Grube E, Laborde JC, Gerckens U, Felderhoff T, Saueren B, Buellesfeld L, et al. Percutaneous implantation of the CoreValve self-expanding valve prosthesis in high-risk patients with aortic valve disease: the Siegburg first-in-man study. Circulation. 2006;114:1616-24.

3. Kempfert J, Rastan AJ, Mohr FW, Walther T. A new self-expanding transcatheter aortic valve for transapical implantation-first in man implantation of the JenaValve. Eur J Cardiothorac Surg. 2011;40:761-3.

4. Modine T, Obadia JF, Choukroun E, Rioufoul G, Sudre A, Laborde JC, et al. Transcutaneous aortic valve implantation using the axillary/subclavian access: feasibility and early clinical outcomes. J Thorac Cardiovasc Surg. 2011;141: 487-91, 491.e1.

5. Bruschi G, Fratto P, De Marco F, Orelia J, Colombo P, Botta L, et al. The transsubclavian retrograde approach for transcatheter aortic valve replacement: single-center experience. J Thorac Cardiovasc Surg. 2010;140:911-5, 915.e1-2.

6. Cockburn J, Trivedi U, Hildick-Smith D. Transaortic transcatheter aortic valve implantation within a previous bioprosthetic aortic valve replacement. Catheter Cardiovasc Interv. 2011;78:479-84.

7. Fraccaro C, Napodano M, Tarantini G, Gasparetto V, Gerosa G, Bianco R, et al. Expanding the eligibility for transcatheter aortic valve implantation: the transsubclavian retrograde approach using the III Generation CoreValve revalving system. JACC Cardiovasc Interv. 2009;2:828-33.

8. Moynagh AM, Scott DJ, Baumbach A, Khavandi A, Brecker SJ, Laborde JC, et al. CoreValve transcatheter aortic valve implantation via the subclavian artery: comparison with the transfemoral approach. J Am Coll Cardiol. 2011;57:634-5.
9. Petronio AS, De Carlo M, Bedogni F, Marzocchi A, Klugmann S, Maisano F, et al. Safety and efficacy of the subclavian approach for transcatheter aortic valve implantation with the CoreValve revalving system. Circ Cardiovasc Interv. 2010; 3:359-66.

10. Modine T, Sudre A, Delhaye C, Fayad G, Lemesle G, Collet F, et al. Transcutaneous aortic valve implantation using the left carotid access: feasibility and early clinical outcomes. Ann Thorac Surg. 2012;93:1489-94.

11. Bauernschmitt R, Schreiber C, Bleiziffer S, Ruge H, Mazzitelli D, Hutter A, et al Transcatheter aortic valve implantation through the ascending aorta: an alternative option for no-access patients. Heart Surg Forum. 2009;12:E63-4.

12. Ruge H, Lange R, Bleiziffer S, Hutter A, Mazzitelli D, Will A, et al. First successful aortic valve implantation with the CoreValve ReValving System via right subclavian artery access: a case report. Heart Surg Forum. 2008;11:E323-4.

13. Moat N. European experience of direct aortic TAVI with a self-expanding prosthesis. Presented at the 47th Society of Thoracic Surgeons Meeting. San Diego: California; 2011.

14. Bapat V. Transcatheter aortic valve replacement with Edwards SAPIEN valve via transaortic route: European multi-center experience. Presented at the Society of Thoracic Surgeons Meeting. San Diego: California; 2011.

15. Dvir D. TCT-125: transcatheter aortic-valve implantation for the treatment of degenerative bioprosthetic surgical valves: results from the Global VIV (Valve-in-Valve) Registry. J Am Coll Cardiol. 2011;58:B36.

16. Piazza N, Bleiziffer S, Brockmann G, Hendrick R, Deutsch MA, Opitz A, et al Transcatheter aortic valve implantation for failing surgical aortic bioprosthetic valve: from concept to clinical application and evaluation (part 2). JACC Cardiovasc Interv. 2011;4:733-42.

17. Piazza N, Bleiziffer S, Brockmann G, Hendrick R, Deutsch MA, Opitz A, et al Transcatheter aortic valve implantation for failing surgical aortic bioprosthetic valve: from concept to clinical application and evaluation (part 1). JACC Cardiovasc Interv. 2011;4:721-32.

18. Thomas M, Schymik G, Walther T, Himbert D, Lefèvre T, Treede H, et al. Oneyear outcomes of cohort 1 in the Edwards SAPIEN Aortic Bioprosthesis European Outcome (SOURCE) registry: the European registry of transcatheter aortic valve implantation using the Edwards SAPIEN valve. Circulation. 2011;124: 425-33.

19. Walther T, Kempfert J, Rastan A, Borger MA, Linke A, Ender J, et al. Transapical aortic valve implantation at 3 years. J Thorac Cardiovasc Surg. 2012;143 326-31.

20. Ussia GP, Barbanti M, Petronio AS, Tarantini G, Ettori F, Colombo A, et al. Transcatheter aortic valve implantation: 3-year outcomes of self-expanding CoreValve prosthesis. Eur Heart J. 2012;33:969-76.

21. Bleiziffer S, Mazzitelli D, Opitz A, Hettich I, Ruge H, Piazza N, et al. Beyond the short-term: clinical outcome and valve performance 2 years after transcatheter aortic valve implantation in 227 patients. J Thorac Cardiovasc Surg. 2012;143: 310-7.

22. Buellesfeld L, Gerckens U, Schuler G, Bonan R, Kovac J, Serruys P, et al. 2-Year follow-up of patients undergoing transcatheter aortic valve implantation using a self-expanding valve prosthesis. J Am Coll Cardiol. 2011;57:1650-7.

23. Eltchaninoff H, Prat A, Gilard M, Leguerrier A, Blanchard D, Fournial G, et al. Transcatheter aortic valve implantation: early results of the FRANCE (FRench Aortic National CoreValve and Edwards) registry. Eur Heart J. 2011;32:191-7.

24. Zahn R, Gerckens U, Grube E, Linke A, Sievert H, Eggebrecht H, et al. Transcatheter aortic valve implantation: first results from a multi-centre real-world registry. Eur Heart J. 2011;32:198-204.

25. Lange R, Bleiziffer S, Mazzitelli D, Elhmidi Y, Opitz A, Krane M, et al. Improvements in transcatheter aortic valve implantation outcomes in lower surgical risk patients—a glimpse into the future. J Am Coll Cardiol. 2012;59:280-7. 